Papers of the Lectures presented at the Annuel Congress of the Belgian Society for Internal Medicine

\title{
UPDATE ON THE TREATMENT OF PITUITARY ADENOMAS: FAMILIAL AND GENETIC CONSIDERATIONS
}

\author{
A.F. Daly, A. Beckers
}

Key words: familial, pituitary, adenoma, AIP, MEN1

\begin{abstract}
Clinically-relevant pituitary adenomas occur with a prevalence of approximately 1 per 1000 population in Belgium. Pituitary adenomas that occur in families are likely to have an important genetic pathophysiological basis. Currently about $5 \%$ of all pituitary adenoma cases have a family history of pituitary adenomas, classically due to multiple endocrine neoplasia type 1 (MEN1) and Carney complex (CNC). Over the last decade we have described non-MEN1/CNC familial pituitary tumours that include all tumour phenotypes, a condition named 'familial isolated pituitary adenoma' (FIPA). Clinical features of FIPA differ from those of sporadic pituitary adenomas in that patients with FIPA are often younger and have larger tumours at diagnosis. Approximately $15 \%$ of FIPA
\end{abstract}

Department of Endocrinology,

Centre Hospitalier Universitaire de Liège,

University of Liège,

Liège, Belgium

Address for Correspondence:

Dr Adrian F. Daly

Department of Endocrinology

Centre Hospitalier Universitaire de Liège

University of Liège

Domaine Universitaire du Sart-Tilman

4000 Liège

Belgium

E-mail: afdaly@student.ulg.ac.be patients have mutations in the aryl hydrocarbon receptor interacting protein gene (AIP), which indicates that FIPA may have a diverse genetic pathophysiology. In this review we examine new findings on the epidemiology of pituitary adenomas, we review familial causes of pituitary adenomas with a particular emphasis on modern clinical testing. In addition the clinical and genetic features of FIPA are described in terms of FIPA representing a useful framework to study the features of pituitary adenomas that occur in a familial setting.

\section{EPIDEMIOLOGY OF PITUITARY TUMOURS: UPDATE}

While many molecular genetic abnormalities have been recognized in the setting of anterior pituitary adenomas, the aetio-pathophysiology of these tumours continues to provoke interest. Some of this interest stems from the growing realization that clinically-relevant pituitary adenomas are considerably more prevalent than previously thought and that these tumours are associated with clinical challenges in terms of symptoms and their complex management. Historically, there has been uncertainty regarding the prevalence of pituitary tumours, with a disconnect between autopsy/radiological series and clinical data. Assessments based on unselected autopsy or MRI data suggest that anterior pituitary adenomas occur frequently. In a meta-analysis, Ezzat et al suggested a mean pituitary tumour prevalence of $14.4 \%$ and $22.5 \%$ 
in autopsy and radiological series, respectively (1). In contrast, population epidemiological studies performed previously indicated that pituitary tumours occur infrequently, at a rate of 190-280 cases/million (1:3571 to 1:5263 individuals) (2). Between these two extremes lies the clinically relevant information, namely the prevalence of clinically-apparent pituitary tumours. Recently, we reported some of the first evidence regarding clinically-apparent pituitary adenoma prevalence in the modern era. These new data suggests that pituitary adenomas occur relatively frequently in the general population, with an overall rate of one case in 1064 of the population (3). This study in a population of nearly 72,000 demonstrated that clinically apparent pituitary adenomas had a prevalence that was 3.5 to 5 times higher than that estimated previously. These results from the Province of Liège in Belgium appear to be of relevance to countries with a similarly developed social and health system. The study probably represents an under-estimation of the number of clinically-active pituitary adenomas, as it was not a screening study but a cross-sectional case-finding study. Screening studies are, however, not possible in a population of this magnitude ( $>70,000$ people); indeed the identification of sub-clinical micro-incidentalomas is of questionable relevance.

A prevalence of about one pituitary adenoma per thousand people is a finding that could have many practical implications. Firstly, increased tumour prevalence can occur due to increased incidence, increased survival or both. Evidence suggests that the underlying rate of occurrence of adenomas today is unchanged as compared with older studies (4). Hence, increased prevalence is likely to be due to a combination of more thorough recognition of cases once they have occurred and greater life expectancy in affected patients. No data are available to support the contention that pituitary adenoma patients are living longer in general. A greater understanding of the impact of disease control on mortality in acromegaly and Cushing's disease, allied with improved neurosurgical and medical care are likely to have had a beneficial effect on survival and, in turn, prevalence. However, probably the most likely reason for the increased prevalence of pituitary adenomas seen in the Liège study was the nature of the methodology. The intensive, case-finding approach in concert with local medical practitioners increased the yield of relevant cases for inclusion beyond that obtained in only referral hospital-based studies.

Disease prevalence rates are required to assess the "burden of disease" in a given population. When calcu- lations of health care or research budget allocations are made, these are usually done with some consideration of the frequency of the disease in the community. Pituitary adenomas, although almost never malignant, can have important attendant costs. The effects of untreated pituitary adenomas are also significant in terms of added morbidity due to hormonal hyper- or hypo-secretion. Pituitary microadenomas are more likely to benefit from curative neurosurgery than larger adenomas, making earlier diagnosis and treatment desirable. For patients not cured by surgery, lifelong medical therapy may be required to reduce hormonal hypersecretion or to replace hormonal deficiencies in other pituitary axes. Regular follow-up of pituitary tumour size using MRI is recommended for clinicallyapparent pituitary adenomas if cure has not been achieved. Treatment-resistant pituitary tumours will require multimodal therapy that also includes radiotherapy. Taken together these facts indicate that a patient with a pituitary tumour may accumulate significant costs over the course of treatment.

\section{GENETICS OF PITUITARY TUMOURS: UPDATE}

\section{MEN1, Carney Complex and MEN4}

The evidence suggesting that clinically apparent pituitary adenomas are 3- to 5-times more common than previously thought increases the need to understand the pathophysiological mechanisms that give rise to these tumours. A wealth of studies has been performed on the molecular genetics of pituitary adenomas in an effort to determine their pathophysiology. Mutations in a series of genes, some relatively frequent and some rare, have been described and characterized in the experimental setting. Chief among these is the gsp gene that encodes the alpha subunit of the Gs, a heterotrimeric G-protein. Activating mutations in gsp lead to constitutive activation of Gs? and increased adenylyl cyclase activity and overproduction of cAMP. Up to $40 \%$ of somatotropinomas have mutations in gsp (5).

Pituitary adenomas with heritable genetic causes are rare and have been described most often in the setting of multiple endocrine neoplasia type 1 (MEN1) and Carney complex (CNC). MEN1 is an autosomal dominant condition that is associated with the occurrence of parathyroid, enteropancreatic and anterior pituitary tumours (6). Endocrine-inactive tumours, such as, lipomas and angiofibromas are also frequently seen in MEN1 patients. The MEN1 gene on chromosome 11q13 (7) encodes the nuclear protein, menin (8). MEN1 ap- 
pears to act as a tumour suppressor gene, and recent data suggest that menin can potentially interact with thousands of genes, 3 ' sites and in chromatin $(9,10)$. To date, over 500 different individual mutations in the MEN1 gene have been described (11), most of which predict a truncated menin protein. However, in $20-30 \%$ of cases suggestive clinically of MEN1, the sequence is normal. About $40 \%$ of patients with MEN1 have pituitary adenomas, and $17 \%$ of cases present with a pituitary tumour $(12,13)$. Such patients who presented with a pituitary adenoma did so 7 years before patients presented with enteropancreatic lesions. Among familial MEN1 cases, pituitary disease was significantly more frequent than in non-familial MEN1 cases (59\% versus $34 \%$, respectively). Females with MEN1 have a somewhat increased chance of having a pituitary adenoma. Prolactinomas predominate among both MEN1 associated and non-MEN1 pituitary adenomas, and the proportions of prolactinomas, $\mathrm{GH}$-secreting, ACTH-secreting, non-secreting and co-secreting adenomas are similar between the MEN1 and non-MEN1 patients. MEN1-related prolactinomas are predominantly macroadenomas (84\%) and higher rates of invasion are seen than in non-MEN1 prolactinomas. The response of MEN1-related prolactinomas to dopamine agonists is poor, with only $44 \%$ of patients being normalized. Pituitary tumours in MEN1 appear to be larger and more aggressive than in patients without MEN1 (8), with macroadenomas being present in $85 \%$ of the former, compared with only $42 \%$ of the sporadic cases. MEN1associated pituitary tumours are significantly more likely to cause signs due to tumour size and have a significantly lower rate of hormonal normalization than non-MEN1 pituitary tumours.

Somatic mutations of the MEN1 gene are not an important factor in the tumourigenesis of non-MEN1 sporadic pituitary adenomas $(14,15)$. Theodoropoulou et al found that menin was detectable in 67768 sporadic non-MEN1 pituitary tumours (16). There is no recognized relationship between the site or type of genetic mutation in the MEN1 gene and the expressed MEN1 disease phenotype, although disease clustering and variations in severity have been recognized (17). Such clusters include the "prolactinoma variant" seen in kindreds from the Burin peninsula in Canada (MEN1BURIN) $(18,19)$. MEN1 has been recognized clinically for some time and consensus guidelines for its investigation and management have been developed (20). Advances in the availability of DNA testing may allow for some practical simplification. Assessment of which patients to test for MEN1 germline mutations depends on their meeting the criteria for the disease (practically, 2 of the 3 constituent major affected tissues: parathyroid, enteropancreatic or pituitary tumours). Assessment of family history is also useful to detect previously unrecognized contributory information, however, it is often practically difficult to exclude a familial case of MEN1 in small kindreds with few living relatives. For index cases in which MEN1 is suspected as a cause for their pituitary tumour, germline DNA analysis of the MEN1 gene would be recommended. In the case where a MEN1 mutation is found, then full family screening for clinical features and biochemical abnormalities (particularly hypercalcaemia) is a good first step. Carriers should be followed closely with regular biochemical, endocrine and appropriate radiological screening for nascent tumours.

CNC is rare with about 500 cases reported to date (21). The primary genetic cause of $C N C$ is mutation of the protein kinase $A$ regulatory subunit $1 \mathrm{~A}$ gene (PRKAR1A) on chromosome 17q22-24 (22). CNC, usually familial, consists of patients with a complex of skin pigmentation, cardiac myxomas, endocrine hypersecretion and schwannomas (23). The main endocrine abnormalities seen in CNC are primary pigmented nodular adrenocortical disease (PPNAD), thyroid tumours and nodules, testicular tumours (large cell calcifying Sertoli cell tumour (LCCSCT), Leydig cell tumours) and acromegaly due to a pituitary adenoma (24). Acromegaly itself is uncommon in CNC (10\% of cases), but about $75 \%$ of patients exhibit asymptomatic elevations in GH, IGF-1 or prolactin levels, or abnormal responses to dynamic pituitary testing. An important feature of CNC-related acromegaly is multifocal hyperplasia of somatomammotropic cells that included non-adenomatous pituitary tissue within the tumours of CNC patients. The zones of hyperplasia were not well demarcated and exhibited increased cellularity and altered reticulin staining that merged with normal pituitary tissue. No consistent genetic abnormalities were seen on comparative genome hybridization. Electron microscopy showed that tumours from acromegalic patients with CNC demonstrate an heterogeneous intracellular structure (25). Acromegaly in CNC develops insidiously and may begin in apparently normal somatomammotrope tissue that undergoes multifocal hyperplasia to form GH/prolactin-secreting adenomas. As in MEN1, sporadic pituitary tumours do not exhibit somatic mutations the PRKAR1A gene (26).

A MEN-1 like syndrome (MEN-4) has been reported recently in rats and in humans and relates to mutations in the CDKN1B gene that encodes p27kip1 $(27,28)$. To 
date only one family with acromegaly, hyperparathyroidism, and renal and testicular cancer has been reported and a further sporadic case with Cushing's disease, a cervical carcinoid tumour, and hyperparathyroidism has been reported (29). MEN4 is a very rare condition and testing remains in the investigational setting.

\section{Familial Isolated Pituitary Adenomas (FIPA)}

Pituitary tumours of all types can occur in multiple members of a single kindred in the absence of MEN1/ $\mathrm{CNC}$, a condition termed familial isolated pituitary adenomas (FIPA). To date we have identified >130 FIPA kindreds in our collaborative series (30), and FIPA families have been reported also by separate research groups $(31,32)$. Mutations in the aryl hydrocarbon receptor interacting protein gene (AIP) in familial acromegaly kindreds have explained the pathophysiology of a proportion of cases. FIPA is not limited to the phenotype of acromegaly, and represents a clinical framework for further genetic study.

In FIPA, pituitary tumours of the same type can present in all affected family members (homogeneous presentation), or affected members can have different types of tumours (heterogeneous presentation). In an international study performed from 2000 to 2005, we identified a total of 64 FIPA families (33). To date, FIPA kindreds with up to four affected members (i.e. subjects with pituitary tumours) have been described. The cohort is comprised equally of families with homogeneous and heterogeneous tumour types in affected members. The frequencies of the various different tumour types in FIPA are: prolactinoma (41\%), somatotropinoma (30\%), non-secreting tumour (13\%), somatolactotropinoma (7\%), gonadotropinoma (4\%), Cushing's disease (4\%) and thyrotropinoma (1\%). First-degree relationship between affected members within families occurs in approximately $75 \%$ of FIPA families. FIPA patients present with pituitary tumours 4 years earlier than their sporadic counterparts. In families with multiple affected generations, the children/grandchildren presented significantly earlier (20 years) than their parents/grandparents. Macroadenomas are seen in $63 \%$ of cases in FIPA kindreds. In terms of specific tumour types, prolactinomas in FIPA are mainly microadenomas occurring in women, while males invariably have macroadenomas; which largely reflects the characteristics of sporadic prolactinomas (34). Prolactinomas in heterogeneous FIPA have higher rates of extension and invasion as compared with sporadic cases. In somatotropinoma patients from FIPA families, half occur as homogeneous acromegaly (familial acromegaly) families, and $50 \%$ in combination with other tumour types (heterogeneous families). Non-secreting pituitary tumours occur in heterogeneous FIPA families and are diagnosed 8 years earlier and have a higher rate of extension/invasion than sporadic tumours. Gonadotropinomas and Cushing's disease can occur rarely in a homogeneous FIPA setting.

In 2006, Vierimaa et al reported the results of a comprehensive genetic study that identified mutations in the aryl hydrocarbon receptor interacting protein (AIP) gene as being associated with the familial presentation of somatotropinomas and prolactinomas (35). Loss of heterozygosity at the AIP locus in tumour samples indicated that these tumours had lost the function of the normal allele in a "second hit" according to the Knudson model. Other families tested negative for AIP mutations. In the FIPA cohort we studied 73 FIPA families from nine countries, and $15 \%$ of the cohort had germline mutations in AIP (36). Ten separate mutations were found, one of which (R304X) was found in a FIPA family that is apparently unrelated to a family from the same country (Italy) with the same mutation reported by Vierimaa et al. Patients with AIP mutations were significantly younger at diagnosis (12 years) than FIPA patients without AIP mutations. Tumours were larger in the AIP mutation-positive groups versus the remainder of the cohort. Only $50 \%$ of those with homogeneous acromegaly had AIP mutations. Importantly, kindreds with strong familiality for pituitary tumours ( 3 or 4 affecteds) can be negative for mutations in AIP (and CDKN1B), which indicates strongly that other genes may be involved in the causation of FIPA.

Further analysis of the disease characteristics of FIPA patients with AIP mutations indicates that tumour and hormonal data are heterogeneous. Over $60 \%$ of AIP mutation positive patients with somatotropinomas had increased GH/IGF-I only and remaining 38\% also had elevated prolactin. Somatotropinoma patients with AIP mutations can be immunohistochemically positive for $\mathrm{GH}$ alone (59\%), $\mathrm{GH}$ and prolactin (33\%) or $\mathrm{GH}$ and $\mathrm{FSH}(8 \%)$.

Since these initial studies, many AIP mutations have been described in the FIPA setting (Figure 1). FIPA families with AIP mutations have also been reported by other groups $(37,38)$. A Q14X mutation, although found with high frequency in Finland, was not found in populations of sporadic adenomas from across the world indicating it as a founder mutation (39). Sporadic pituitary tumour patients infrequently have AIP mutations, although they are not entirely absent (40). Over- 


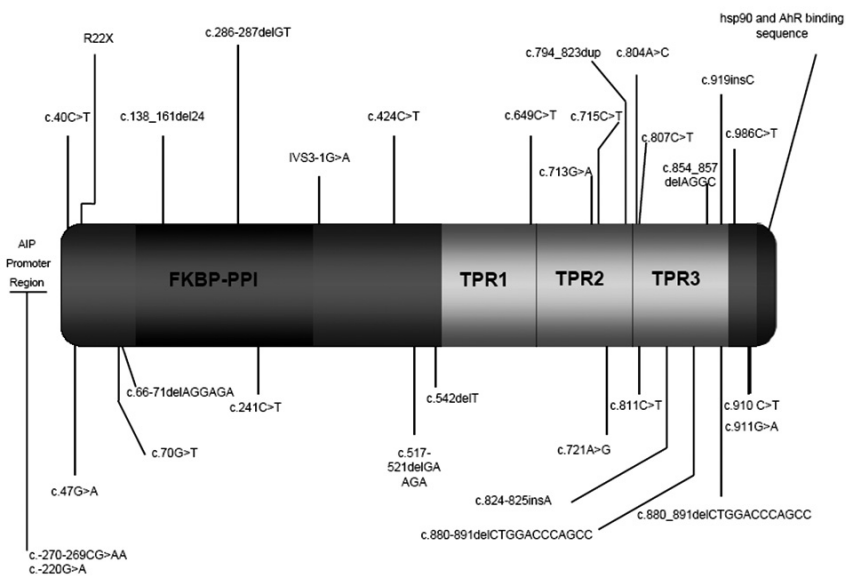

Figure 1. Mutations in the aryl hydrocarbon receptor interacting protein gene (AIP) reported in FIPA and sporadic pituitary tumour patients (current September 2008). FKBPPPI = FK506 binding protein-type peptidyl-prolyl cistrans isomerase; TPR = tetratricopeptide repeat domain; hsp90 = heat-shock protein 90; AhR = Aryl hydrocarbon receptor.

all, sporadic pituitary tumour patients with AIP mutations seem to present at a young age and mainly with somatotropinomas, although other pituitary tumour types do occur (41). Cazabat et al reported that in a total of 154 sporadic patients with acromegaly, five patients (3.2\%) demonstrated AIP mutations. Studies in other tumours have revealed no firm evidence of germline AIP mutations as a potentially causative or contributory factor (42).

The manner by which AIP mutations cause pituitary adenomas in FIPA and apparently sporadic cases is largely unknown. Many AIP mutations described to date would involve truncations of the AIP protein, with the loss of a tetratricopeptide repeat domain and the carboxy terminal that are important for interactions with other proteins such as heat shock protein 90 (hsp90) and the aryl hydrocarbon receptor $(43,44,45,46,47)$. Other missense mutations (e.g. R271W) involve highly conserved amino acids, which may alter AIP function in other ways. Whether various mutated versions of AIP are actually expressed or undergo mRNA degradation is presently unknown A variety of cellular effects are potentially related to AIP activity, of which modulation of phosphodiesterase PDE4A5 and phosphodiesterase PDE2A activities are of interest $(48,49)$. Leontiou and colleagues found that over-expression of wild-type AIP in HEK 293, human embryonic lung fibroblast (TIG 3) and the rat somatomammotroph $(\mathrm{GH} 3)$ cell lines led to marked reductions in measures of cell proliferation
(32). When a variety of mutated forms of AIP were expressed in the cell lines (including a number of mutations described in the setting of FIPA), suppression of cell proliferation was negated. Also protein-protein interactions between AIP and PDE4A5 were disrupted by mutations in AIP. Immunohistochemical data revealed that in normal pituitary, AIP co-localized only with $\mathrm{GH}$ and prolactin secreting cells and was found in association with secretory granules. In sporadic tumours AIP protein is expressed in all tumour types, however, it was only expressed in cytoplasm in prolactinomas, non-functioning and Cushing disease tumours; AIP appeared to co-localize with secretory granules in somatotropinomas. Study of Aip knockout models is at an early stage and no specific information on pituitary status has been reported $(50,51)$. Given the important role of AhR in mediating the biological effects on dioxin, the potential for pituitary tumourigenesis having its roots in environmental toxins has been suggested. Data from one of the most exhaustively studied industrial accidents involving dioxin exposure would argue otherwise. Pesatori et al studied the incidence of pituitary tumours in the Seveso population exposed to 2,3,7,8-tetrachlorodibenzo-para-dioxin after an accident in 1976 (52). They found no significant increase in the incidence of pituitary tumours in this region, although given the often indolent nature of pituitary adenoma formation may require longer follow up. Furthermore, a more intensive study of patients with very high clinical exposure to dioxins (e.g. those with chloracne and high dioxin titers) may be useful to finally discount the link between environmental dioxin exposure and increased rates of pituitary tumourigenesis.

From a clinical perspective, it should be emphasized that clinically relevant pituitary adenomas are more common than previously thought (1:1000) and occur in a familial setting in about $5 \%$ of cases overall. Therefore, careful questioning regarding family history of pituitary disease should be part of the workup of all patients with pituitary adenomas. The discovery linking mutations in AIP to pituitary tumours occurring in a family setting has provided particularly important impetus, but the molecular pathophysiology remains very unclear. Families bearing AIP mutations have more aggressive pituitary tumours in affected members, and are often seen at a much younger age than is usual in the sporadic setting. Genetic screening for AIP mutations in patients with sporadic pituitary adenomas and in relatives of those bearing AIP mutations requires careful consideration. There remains divergence about the penetrance of pituitary adenomas among kindreds with 
AIP mutations, making the true risk of disease in mutation carriers unclear. We suggest that the penetrance of pituitary disease in AIP mutation-bearing FIPA kindreds may be relatively high, at least 33\% in the largest kindreds (53). For newly recognized FIPA families we would recommend initial sequencing of the full length of the AIP gene in at least one affected individual. This remains an investigational study that is not offered commercially at this time, although the relatively short length of the AIP gene makes sequencing relatively uncomplicated. Sequencing of the AIP gene from somatic DNA in patients who have undergone pituitary neurosurgery is somewhat more complex but has led to the identification of AIP mutations using the multiplex ligation-dependent probe amplification analysis (MLPA) methodology. MLPA of germline DNA is also useful for the initial identification of large genetic deletions of the AIP gene or more extensive deletions including the AIP gene (54). In the case of relatives of patients with AIP mutation-related pituitary adenomas, we suggest constructing a careful genealogical tree and undertaking targeted germline AIP screening to identify carriers. As tumours in individuals with AIP mutations are more aggressive and occur at an earlier age, there is potential value in identifying carriers for the purpose of performing MRI and hormonal testing; the ultimate aim would be to diagnose tumours at as small a size as possible in order to permit potentially curative pituitary neurosurgical resection. In the absence of a tumour on MRI, follow-up of mutation carriers can be performed on a regular basis (yearly), relying predominantly on clinical symptoms and basal hormonal tests (IGF-I and prolactin).

Widespread AIP screening in unselected patients with sporadic pituitary adenomas is not warranted at this time. Young patients with aggressive pituitary tumours are also more likely to carry AIP mutations, and testing for AIP mutations among apparently sporadic populations should at this time be limited to such young cases.

\section{REFERENCES}

1. Ezzat S, Asa SL, Couldwell WT, et al. The prevalence of pituitary adenomas: a systematic review. Cancer 2004Aug 1;101(3):6139.

2. Davis JR, Farrell WE, Clayton RN. Pituitary tumours. Reproduction 2001 Mar;121(3):363-71.

3. Daly AF, Rixhon M, Adam C, Dempegioti A, Tichomirowa MA, Beckers A. High prevalence of pituitary adenomas: a cross-sectional study in the province of Liege, Belgium. J Clin Endocrinol Metab 2006 Dec;91(12):4769-75.
4. Hemminki K, Försti A, Ji J. Incidence and familial risks in pituitary adenoma and associated tumours. Endocr Relat Cancer 2007 Mar;14(1):103-9.

5. Asa SL, Ezzat S. Genetics and proteomics of pituitary tumours. Endocrine 2005 Oct;28(1):43-7.

6. Agarwal SK, Lee Burns A, Sukhodolets KE, et al. Molecular pathology of the MEN1 gene. Ann NYAcad Sci 2004; 1014:189-98.

7. Larsson C, Skogseid B, Oberg K, Nakamura Y, Nordenskjold M. Multiple endocrine neoplasia type 1 gene maps to chromosome 11 and is lost in insulinoma. Nature 1988 Mar 3;332(6159):85-7.

8. Chandrasekharappa SC, Guru SC, Manickam P, et al. Positional cloning of the gene for multiple endocrine neoplasia-type 1. Science 1997 Apr 18;276(5311):404-7.

9. Scacheri PC, Davis S, Odom DT, et al. Genome-wide analysis of menin binding provides insights into MEN1 tumourigenesis. PLoS Genet 2006 Apr;2(4):e51.

10. Agarwal SK, Impey S, McWeeney S, et al. Distribution of meninoccupied regions in chromatin specifies a broad role of menin in transcriptional regulation. Neoplasia 2007 Feb;9(2):101-7.

11. Lemos MC, Thakker RV. Multiple endocrine neoplasia type 1 (MEN1): analysis of 1336 mutations reported in the first decade following identification of the gene. Hum Mutat 2007 Aug 24; [Epub ahead of print].

12. Vergès $B$, Boureille $F$, Goudet $P$, et al. Pituitary disease in MEN type 1 (MEN1): data from the France-Belgium MEN1 multicenter study. J Clin Endocrinol Metab 2002 Feb;87(2):457-65.

13. Beckers A, Betea D, Valdes Socin H, Stevenaert A. The treatment of sporadic versus MEN1-related pituitary adenomas. J Int Med 2003; 253: 599-605.

14. Zhuang Z, Ezzat SZ, Vortmeyer AO, et al. Mutations of the MEN1 tumour suppressor gene in pituitary tumours. Cancer Res 1997 Dec 15;57(24):5446-51.

15. Poncin J, Stevenaert A, Beckers A. Somatic MEN1 gene mutation does not contribute significantly to sporadic pituitary tumourigenesis. Eur J Endocrinol 1999 Jun;140(6):573-6.

16. Theodoropoulou M, Cavallari I, Barzon L, et al. Differential expression of menin in sporadic pituitary adenomas. Endocr Relat Cancer 2004 Jun; 11(2):333-44.

17. Beckers A, Abs R, Reyniers E, et al. Variable regions of chromosome 11 loss in different pathological tissues of a patient with the multiple endocrine neoplasia type I syndrome. J Clin Endocrinol Metab 1994 Nov;79(5):1498-502.

18. Farid NR, Buehler S, Russell NA, Maroun FB, Allerdice P, Smyth HS. Prolactinomas in familial multiple endocrine neoplasia syndrome type I. Relationship to HLA and carcinoid tumours. Am J Med 1980 Dec;69(6):874-80.

19. Olufemi SE, Green JS, Manickam P, et al. Common ancestral mutation in the MEN1 gene is likely responsible for the prolactinoma variant of MEN1 (MEN1Burin) in four kindreds from Newfoundland. Hum Mutat 1998;11(4):264-9.

20. Brandi ML, Gagel RF, Angeli A, et al. Guidelines for diagnosis and therapy of MEN type 1 and type 2. J Clin Endocrinol Metab 2001; 86(12): 5658-71.

21. Boikos SA, Stratakis CA. Carney complex: the first 20 years. Curr Opin Oncol 2007; 19: 24-9.

22. Casey $M$, Mah $C$, Merliss $A D$, et al. Identification of a novel genetic locus for familial cardiac myxomas and Carney complex. Circulation 1998; 98: 2560-6.

23. Stratakis CA, Kirschner LS, Carney JA. Clinical and molecular features of the Carney complex: diagnostic criteria and recommendations for patient evaluation. J Clin Endocrinol Metab 2001; 86(9): 4041-6. 
24. Stergiopoulos SG, Stratakis CA. Human tumours associated with Carney complex and germline PPKAR1A mutations: a protein kinase A disease! FEBS Letters 2003; 546: 59-64.

25. Kurtkaya-Yapicier O, Scheithauer BW, Carney JA, et al. Pituitary adenoma in Carney complex: an immunohistochemical, ultrastructural,and immunoelectron microscopic study. Ultrastruct Pathol 2002 Nov-Dec;26(6):345-53.

26. Kaltsas GA, Kola B, Borboli N, et al. Sequence analysis of the PRKAR1A gene in sporadic somatotroph and otherpituitary tumours. Clin Endocrinol (Oxf) 2002 Oct;57(4):443-8.

27. Fritz A, Walch A, Piotrowska K, et al. Recessive transmission of a multiple endocrine neoplasia syndrome in the rat. Cancer Res 2002 Jun 1;62(11):3048-51.

28. Pellegata NS, Quintanilla-Martinez L, Siggelkow H, et al. Germline mutations in P27Kip1 cause a multiple endocrine neoplasia syndrome in rats and humans. Proc Natl Acad Sci USA 2006 Oct 17;103(42):15558-63.

29. Georgitsi M, Raitila A, Karhu A, et al. Germline CDKN1B/ p27Kip1 mutation in multiple endocrine neoplasia.J Clin Endocrinol Metab 2007;92(8):3321-5.

30. Beckers A, Daly AF. The clinical, pathological, and genetic features of familial isolated pituitary adenomas. Eur J Endocrinol 2007 Oct; 157(4):371-82.

31. Villa C, Magri F, Morbini P, et al. Silent Familial Isolated Pituitary Adenomas: Histopathological and Clinical Case Report. Endocr Pathol 2008 Mar 4 [Epub ahead of print].

32. Leontiou CA, Gueorguiev M, van der Spuy J, et al. The role of the AIP gene in familial and sporadic pituitary adenimas. J Clin Endocrinol Metab 2008 Apr 17 [Epub ahead of print].

33. Daly AF, Jaffrain-Rea ML, Ciccarelli A, et al. Clinical characterization of familial isolated pituitary adenomas. J Clin Endocrinol Metab 2006 Sep;91(9):3316-23. Epub 2006 Jun 20.

34. Ciccarelli A, Daly AF, Beckers A. The epidemiology of prolactinomas. Pituitary 2005;8(1):3-6.

35. Vierimaa O, Georgitsi M, Lehtonen R, et al. Pituitary adenoma predisposition caused by germline mutations in the AIP gene. Science 2006;312(5777):1228-30.

36. Daly AF, Vanbellinghen JF, Khoo SK, et al. Aryl hydrocarbon receptor-interacting protein gene mutations in familial isolated pituitary adenomas: analysis in 73 families. J Clin Endocrinol Metab 2007 May;92(5):1891-6.

37. Iwata T, Yamada S, Mizusawa N, Golam HM, Sano T, Yoshimoto $\mathrm{K}$. The aryl hydrocarbon receptor-interacting protein gene is rarely mutated in sporadic $\mathrm{GH}$-secreting adenomas. Clin Endocrinol (Oxf) 2007 Apr;66(4):499-502.

38. Toledo RA, Lourenco DM Jr, Liberman B, et al. Germline mutation in the aryl hydrocarbon receptor interacting protein gene in familial somatotropinoma. J Clin Endocrinol Metab. 2007 May;92(5):1934-7.

39. Yu R, Bonert V, Saporta I, Raffel LJ, Melmed S. AIP variants in sporadic pituitary adenomas. J Clin Endocrinol Metab 2006 Dec;91(12):5126-9.

40. Barlier A, Vanbellinghen JF, Daly AF,et al. Mutations in the aryl hydrocarbon receptor interacting protein gene are not highly prevalent among subjects with sporadic pituitary adenomas. J Clin Endocrinol Metab 2007 May;92(5):1952-5. Epub 2007 Feb 13.
41. Georgitsi M, Raitila A, Karhu A, et al. Molecular diagnosis of pituitary adenoma predisposition caused by aryl hydrocarbon receptor-interacting protein gene mutations. Proc Natl Acad Sci USA 2007 Mar 6;104(10):4101-5.

42. Georgitsi M, Karhu A, Winqvist R, et al. Mutation analysis of aryl hydrocarbon receptor interacting protein (AIP) gene in colorectal, breast, and prostate cancers. Br J Cancer 2007 Jan 29;96(2):352-6.

43. Petrulis JR, Perdew GH. The role of chaperone proteins in the aryl hydrocarbon receptor core complex. Chem Biol Interact 2002; 141(1-2):25-40.

44. Bell DR, Poland A. Binding of aryl hydrocarbon receptor (AhR) to AhR-interacting protein. The role of hsp90.J Biol Chem 2000; 275(46):36407-14.

45. Meyer BK, Petrulis JR, Perdew GH. Aryl hydrocarbon (Ah) receptor levels are selectively modulated by hsp90-associated immunophilin homolog XAP2. Cell Stress Chaperones 2000; 5(3):243-54.

46. Carver LA, LaPres JJ, Jain S, Dunham EE, Bradfield CA. Characterization of the Ah receptor-associated protein, ARA9. J Biol Chem 1998; 273(50):33580-7.

47. Meyer BK, Perdew GH. Characterization of the AhR-hsp90-XAP2 core complex and the role of the immunophilin-related protein XAP2 in AhR stabilization. Biochemistry 1999; 38(28):8907-17.

48. Bolger GB, Peden AH, Steele MR, et al. Attenuation of the activity of the CAMP-specific phosphodiesterase PDE4A5 by interaction with the immunophilin XAP2. J Biol Chem 2003 Aug 29;278(35):33351-63.

49. de Oliveira SK, Hoffmeister M, Gambaryan S, Muller-Esterl W, Guimaraes JA, Smolenski AP. Phosphodiesterase 2A Forms a Complex with the Co-chaperone XAP2 and Regulates Nuclear Translocation of the Aryl Hydrocarbon Receptor. J Biol Chem 2007 May 4;282(18):13656-63.

50. Lin BC, Sullivan R, Lee Y, Moran S, Glover E, Bradfield CA. Deletion of the aryl hydrocarbon receptor-associated protein 9 leads to cardiac malformation and embryonic lethality. J Biol Chem 2007 Dec 7;282(49):35924-32.

51. Lin BC, Nguyen LP, Walisser JA, Bradfield CA. A Hypomorphic Allele of Aryl-hydrocarbon Receptor-associated-9 Produces a Phenocopy of the Ahr Null. Mol Pharmacol 2008 Jul 31. [Epub ahead of print]

52. Pesatori A, Baccarelli A, Consonni D, et al. Aryl hydrocarbon receptor interacting protein and pituitary adenomas: a population-based study on subjects exposed to dioxin after the Seveso, Italy, accident. Eur J Endocrinol 2008 Sep 11. [Epub ahead of print]

53. Naves LA, Daly AF, Vanbellinghen JF, et al. Variable pathological and clinical features of a large Brazilian family harboring a mutation in the aryl hydrocarbon receptor-interacting protein gene. Eur J Endocrinol 2007 Oct;157(4):383-91.

54. Georgitsi M, Heliövaara E, Paschke R, et al. Large genomic deletions of aryl hydrocarbon receptor interacting protein (AIP) gene in pituitary adenoma predisposition. J Clin Endocrin Metab Epub July 15, 2008: doi:10.1210/jc.2008-1003. 